\title{
Stricture length and etiology as preoperative independent predictors of recurrence after urethroplasty: A multivariate analysis of 604 urethroplasties
}

\author{
Adam S. Kinnaird, MD; Max A. Levine, MD; Druvtej Ambati; Jeff D. Zorn, MD; Keith F. Rourke, MD, FRCSC
}

Division of Urology, Department of Surgery, University of Alberta, Edmonton, $A B$

Cite as: Can Urol Assoc J 2014;8(5-6):e296-300. http://dx.doi.org/10.5489/cuaj.1661 Published online May 21, 2014.

\section{Abstract}

Introduction: We determine the preoperative identifiable risk factors during staging that predict stricture recurrence after urethroplasty.

Methods: We conducted a retrospective review of all urethroplasties performed at a Canadian tertiary referral centre from 2003 to 2012 . Failure was defined as a recurrent stricture $<16 \mathrm{Fr}$ on cystoscopic assessment. Multivariate analysis was calculated by Cox proportional hazard regression.

Results: In total, 604 of 651 (93\%) urethroplasties performed had adequate data with a mean follow-up of 52 months. Overall urethral patency was $90.7 \%$ with failures occurring between 2 weeks and 77 months postoperatively. The average time to recurrence was 11.7 months, with most patients with recurrence within 6 months (42/56; 75\%). Multivariate regression identified Lichen sclerosus, iatrogenic, and infectious etiologies to be independently associated with stricture recurrence with hazard ratios (HR) $(95 \%$ confidence interval) of 5.9 (2.1-16.5; $p \leq 0.001), 3.4(1.2-10 ; p=0.02)$, and $7.3(2.3-23.7 ; p \leq 0.001)$, respectively. Strictures $\geq 5 \mathrm{~cm}$ recurred significantly more often (13.8\% vs. 5.9\%) with a HR 2.3 (1.2-4.5; $p \leq 0.01$ ). Comorbidities, smoking, previous urethroplasty, stricture location and an age $\geq 50$ were not associated with recurrence.

Conclusion: Urethroplasty in general is an excellent treatment for urethral stricture with patency rates approaching 91\%. While recurrences occur over 6 years after surgery, most $(75 \%)$ recur within the first 6 months. Long segment strictures $(\geq 5 \mathrm{~cm})$, as well as Lichen sclerosus, infectious and iatrogenic etiologies, are associated with increased risk of recurrence. Limitations include the retrospective, single-centre nature of the study and the $7 \%$ loss to follow-up due to the centre being a regional referral one.

\section{Introduction}

Urethral stricture has an estimated incidence of $0.6 \%$ with treatment costs of about $\$ 200$ million annually in the United States. ${ }^{1}$ While stricture classically presents with lower urinary tract symptoms and acute urinary retention, a propor- tion of men $(7 \%)$ present with a life-threatening condition. ${ }^{2}$ The most common etiologies differ worldwide, with causes of stricture classified as: iatrogenic, traumatic, Lichen sclerosus, infectious, hypospadias, radiation exposure and idiopathic. ${ }^{3}$ Anatomically, stricture or stenosis may occur anywhere along the urethra, defined as spongiofibrosis of the anterior (pendulous/bulbar, about $15 \mathrm{~cm}$ in length) urethra or as a posterior (membranous/prostatic, about $3 \mathrm{~cm}$ ) urethral stenosis. ${ }^{4}$

Among several treatment strategies, including dilation and direct visual internal urethrotomy (DVIU), urethroplasty has emerged as the cost-effective management option for almost all strictures and remains the gold standard for longer, complex or recalcitrant strictures. ${ }^{5,6}$ Despite this, longterm follow-up shows failures do occur in $2 \%$ to $30 \%$ of patients depending on the type of urethroplasty employed., ${ }^{7,8}$ Therefore, "What factors are associated with stricture recurrence?" remains an important question. In one series, 5-year stricture-free survival combining all urethroplasties was 79\%; length, comorbidities and previous procedures were associated with recurrence. ${ }^{9}$

The purpose of this study was to use a large series of urethroplasties to assess for preoperatively generally identifiable risk factors that may lead to stricture recurrence after urethroplasty.

\section{Methods}

Appropriate Health Ethics Research Board approval was granted (MS1_Pro00003680) to create a prospectively maintained, retrospective database of all urethral reconstructions performed between 2003 and 2012. A single surgeon at an academic tertiary referral centre performed all operations and data were collected using patient hospital and electronic medical records. Data included age, comorbidities, smoking status and previous procedures, as well as stricture length, location and etiology. All patients were staged with preoperative cystoscopy and retrograde urethrogram. 
Patients were followed up in clinic within 1 month postoperatively, underwent cystoscopic evaluation at 6 months and reviewed as required for recurrent or intractable voiding symptoms. If a concerning feature was seen at the 6-month cystoscopy, then the patient was booked for surveillance cystoscopy at 12-month intervals. If cystoscopy at 6 months looked very favourble, patients were then followed symptomatically. All emergency room visits and referrals to all other urologists in the region were tracked through our electronic medical record and therefore captured in the database.

Kaplan-Meier survival curves and Cox proportional hazard regression analysis were performed on SPSS software. Variables were constructed categorically and included: age $\geq 50$, previous urethroplasty, Charlson comorbidity score $\geq 1$, current smoker (defined as smoking within 1 month preoperatively), stricture length $\geq 5 \mathrm{~cm}$, location (anterior vs. posterior vs. panurethral), and etiology (trauma/hypospadias/ Lichen sclerosus/radiation/iatrogenic/infectious/idiopathic). An age of 50 was used as a cutoff point as this represented the mean age of the study population. A two-sided $p$ value $\leq 0.05$ was considered significant.

\section{Results}

In total, 651 urethroplasties were performed during the study period with complete follow-up in 604 (93\%) patients. The mean follow-up was 52 months. To be included in the study, patients had to have had at least a 6-month cystoscopy or presented with recurrent stricture prior to the 6-month follow-up.

The mean patient age was 44.5 years with 123 (20.4\%) having had a previous reconstruction. Virtually all patients $(84 \%)$ had undergone prior dilation or DVIU. In total, 148 patients $(25 \%)$ had a Charlson comorbidity score of 1 or more and 117 (19\%) patients were current smokers as defined by smoking within 1 month of surgery (data available for 558 out of 604 patients). ${ }^{10}$

The average stricture length was $4.8 \mathrm{~cm}$ and strictures were located in the anterior urethra in $502(83.1 \%)$ patients, posterior urethra in $74(12.3 \%)$, and panurethral in $28(4.6 \%)$. The most commonly identifiable etiology was trauma in 155 $(25.7 \%)$, followed by hypospadias in $64(10.6 \%)$, Lichen sclerosus in $58(9.6 \%)$, iatrogenic in $56(9.3 \%)$, radiation (brachytherapy/external beam) in $23(3.8 \%)$, and infectious in $17(2.8 \%)$. The cause was diagnosed as idiopathic in $231(38.2 \%)$, which is similar to typical rates found in the literature (Table 1). ${ }^{9}$

Overall urethral patency was $90.7 \%$ (548/604). Strictures recurred in as early as 2 weeks and as late as 77 months postoperatively. Of the failures, the average time to recurrence was 11.7 months, with most strictures (42/56; 75\%) recurring within 6 months.

\section{Table 1. Clinicopathologic demographics}

\begin{tabular}{lc}
\hline Patient data & $\begin{array}{c}\text { No. (\%) } \\
\mathbf{n}=604\end{array}$ \\
\hline Mean age & 44.5 \\
Mean follow-up (months) & 52 \\
Previous reconstruction & $123(20 \%)$ \\
Charlson comorbidity score $\geq 1$ & $148(25 \%)$ \\
Smoking & $117(19 \%)$ \\
Stricture characteristics: & \\
Average length & $4.8 \mathrm{~cm}$ \\
Location & \\
Anterior & $502(83 \%)$ \\
Posterior & $74(12 \%)$ \\
Panurethral & $28(5 \%)$ \\
Etiology & \\
Trauma & $155(26 \%)$ \\
Hypospadias & $64(11 \%)$ \\
Lichen sclerosus & $58(10 \%)$ \\
latrogenic & $56(9 \%)$ \\
Radiation & $23(4 \%)$ \\
Infectious & $17(3 \%)$ \\
Idiopathic & $231(38 \%)$ \\
\hline
\end{tabular}

Multivariate regression identified Lichen sclerosus, iatrogenic and infectious etiologies as independently associated with stricture recurrence with hazard ratios $(\mathrm{HR})(95 \%$ confidence interval $[\mathrm{Cl}])$ of $5.9(2.1-16.5 ; p \leq 0.001), 3.4(1.2-10$; $p=0.02)$, and $7.3(2.3-23.7 ; p \leq 0.001)$, respectively (Table 2 , Fig. 1). Strictures of $\geq 5 \mathrm{~cm}$ recurred significantly more often $(13.8 \%$ vs. $5.9 \%)$ with a HR $2.3(1.2-4.5 ; p \leq 0.01)$ (Fig. 2). Comorbidities, smoking, previous urethroplasty, stricture location and an age $\geq 50$ were not associated with stricture recurrence.

\section{Discussion}

While an overall urethral patency rate of about $91 \%$ is encouraging, this means that about 1 in 10 patients will require further management of their disease. We have identified several preoperatively identifiable risk factors for stricture recurrence.

Strictures of $\geq 5 \mathrm{~cm}$ were found to increase recurrence from $6 \%$ to $14 \%$. We chose $5 \mathrm{~cm}$ as a cutoff for 2 reasons. First, the mean length of stricture in our data was $4.8 \mathrm{~cm}$; second, a 5-cm cutoff was used in a recent systematic review, which had an average stricture length of $4.9 \mathrm{~cm}$ and a statistically significant difference in failure rate of $12.4 \% \mathrm{vs}$. $16.6 \%$, favouring strictures shorter than $5 \mathrm{~cm} .{ }^{11}$ The clinical significance of increased stricture length is likely the type of procedure and tissue transfer required to reconstruct longer strictures. Eltahawy and colleagues found a highly successful rate of $98.8 \%$ for strictures measuring 0.5 to $4.5 \mathrm{~cm}$ using excision and primary anastomosis, while several other 


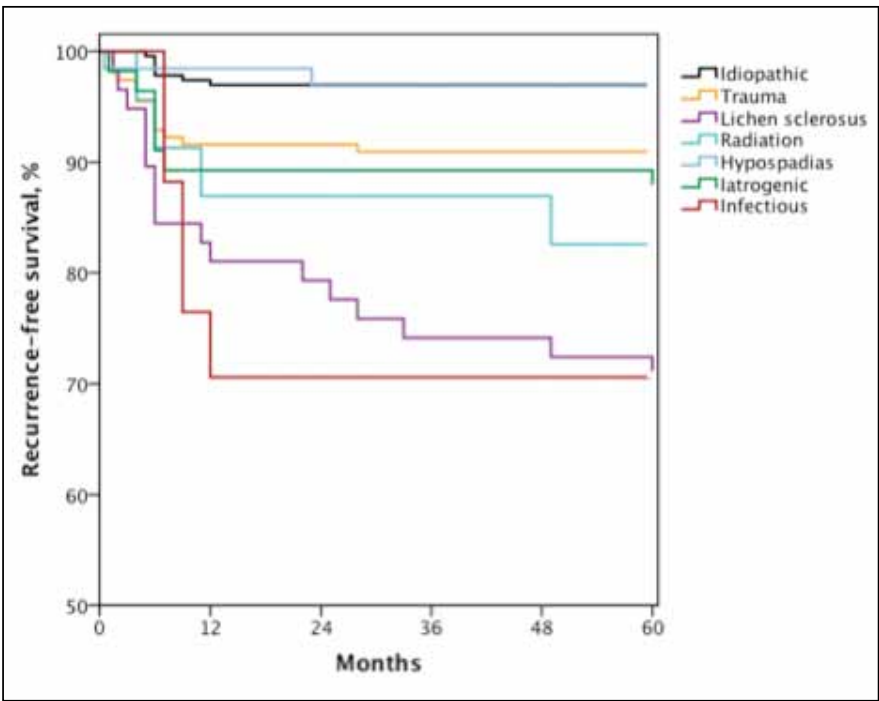

Fig. 1. Recurrence-free survival stratified by stricture etiology.

series have used excision and primary anastomosis (EPA) for bulbar strictures up to $5 \mathrm{~cm}$ in length. . $^{8,12,13}$ In contrast, most long segment strictures will be repaired using flaps or grafts known to have lower long-term success potentially due to ischemic tissue contracture or the requirement for multiple techniques. ${ }^{14}$ When a longer stricture is reconstructed, there is more tissue predisposed to forming stricture present and there is a larger area for ischemic contracture to occur thus likely increasing the rate of recurrence.

We found that Lichen sclerosus highly correlates with stricture recurrence with a HR of $5.9(p \leq 0.001)$. The main difference between Lichen sclerosus and other etiologies is that Lichen sclerosus strictures tended to recur even after

Table 2. Multivariate analysis of factors associated with stricture recurrence

\begin{tabular}{lcc}
\hline Factor & Hazard ratio (95\% Cl) & p value \\
\hline Age $\geq 50$ & $0.8(0.5-1.5)$ & 0.53 \\
Comorbidity score $\geq 1$ & $1.5(0.8-2.9)$ & 0.20 \\
Smoking & $1.1(0.58-2.1)$ & 0.76 \\
Previous reconstruction & $1.0(0.49-2.0)$ & 0.98 \\
Stricture length $\geq 5 \mathrm{~cm}$ & $2.3(1.2-4.5)$ & 0.01 \\
Location & & \\
Anterior & $0.49(0.2-1.2)$ & 0.12 \\
Posterior & $0.67(0.3-1.7)$ & 0.39 \\
Panurethral & $1.4(0.38-5)$ & 0.63 \\
Etiology & & \\
Trauma & $2.6(0.98-6.9)$ & 0.06 \\
Lichen sclerosus & $5.9(2.1-16.5)$ & $<0.001$ \\
Radiation & $3.3(0.8-14)$ & 0.10 \\
Hypospadias & $0.8(0.15-3.9)$ & 0.74 \\
latrogenic & $3.4(1.2-10)$ & 0.02 \\
Infectious & $7.3(2.3-23.7)$ & $<0.001$ \\
\hline Cl: confidence interval. & &
\end{tabular}

several years (Fig. 1). Lichen sclerosus has been implicated with failure after repeat urethroplasty; we believe that the reason for recurrence is that the underlying disease has not been adequately treated such that it is not truly treatment failure, but rather disease progression as part of the natural history of Lichen sclerosus. ${ }^{15,16}$ Infectious etiology is another risk factor for recurrence. These strictures are secondary to Reiter's syndrome or Fournier's gangrene where significant tissue inflammation and necrosis may occur. These surgeries have an increased level of technical difficulty and likely have poor recipient vascularity and graft bed with possibly impaired imbibition, inosculation and formation of granulation tissue. Similarly, iatrogenic strictures were associated with recurrence. These strictures were mainly found in the posterior urethra from a transurethral resection of the prostate, KTP laser prostatectomy, cryosurgery and radical prostatectomy and were housed in a hostile environment from mechanical, electrical and thermal tissue ablation. Radiation and hypospadias etiologies were not associated with stricture recurrence. This may be due to a combination of patient selection and surgical technique. For example, in the setting of radiation-induced stenoses, ensuring that patients lack cavitation or necrosis of the urethra, as well as emphasizing adequate exposure with judicious use of infrapubectomy, is critical. Anecdotally, when tissue transfer is required, flaps may perform better than grafts likely due to the hostile periurethral environment post-radiation. Hypospadias repairs are almost exclusively performed in a staged approach, which allows for assessment of graft maturation prior to tubularization and interposition of robust flaps during second stage tubularization.

The average time to recurrence was about 1 year, with $75 \%$ recurring within the first 6 months. Failure within the

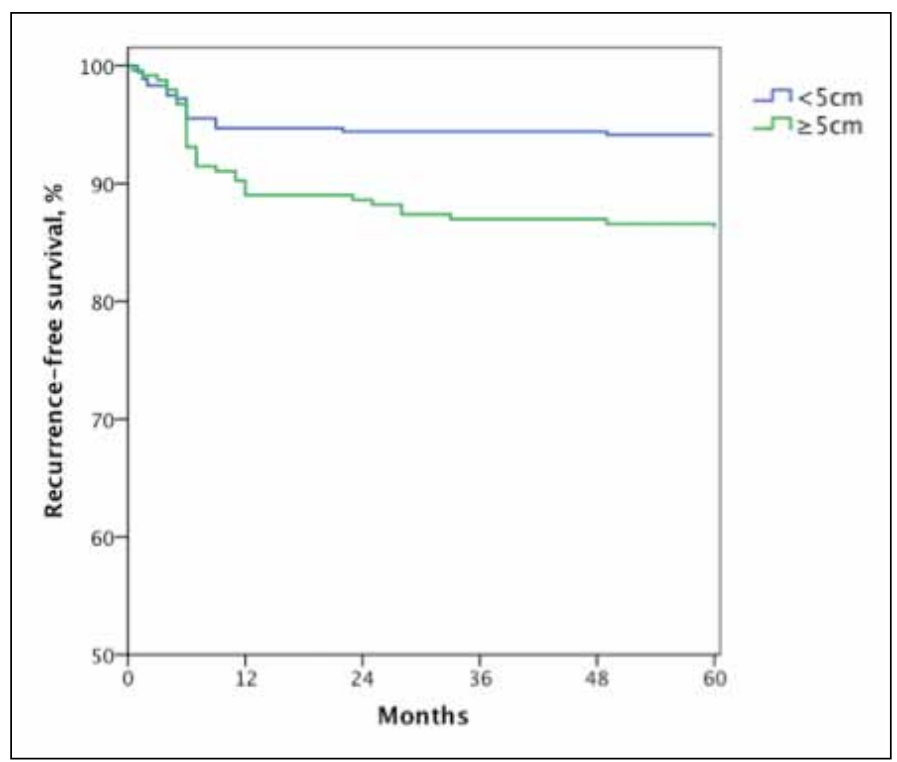

Fig. 2. Recurrence-free survival stratified by stricture length of $<5 \mathrm{~cm}$ vs. $\geq 5 \mathrm{~cm}$. 
first year has been noted in other series, with well over half $(57 \%)$ of the decline in 5 -year stricture-free survival occurring within the first year of follow-up. ${ }^{9}$ Recurrences continue to accrue over time, however, at a slower rate. This begs the question as to what is happening during the first 6 months to a year that is causing stricture recurrence. While technical failure, subclinical infection, poor graft take or maturation of the anastomosis/graft are possible reasons, another explanation is based on the normal physiological process of wound healing and scar formation. The inflammatory and proliferative stages of healing occur in the first 3 weeks, yet the affected tissue remains metabolically active with myofibroblasts reshaping the wound for up to 1 year during the remodeling phase potentially leading to recurrence. ${ }^{17}$ After this time the tissue may have achieved a longer-term stability unless the tissue has an underlying pathological process as we have hypothesized for Lichen sclerosus recurrences.

As strictures are diagnosed more commonly in older patients, with a significantly increased incidence seen in the mid-fifties, it is important to explore how aging effects outcome. ${ }^{1}$ In the $38 \%$ of urethroplasties performed on men over 50, we found no correlation to recurrence. This is similar to results from another study that found urethroplasty was an effective strategy in the elderly. ${ }^{18}$

Repeat urethroplasty is a viable option for stricture recurrence. ${ }^{15}$ In the $20 \%$ of our urethroplasties having undergone previous repair, we found that previous urethroplasty does not contribute to treatment failure.

Comorbid status was not associated with recurrence as previously suggested..$^{9}$ Similarly, we did not find that smoking adversely affected outcome. However, this is an area of controversy; this same study found that smoker comorbidities, such as chronic obstructive pulmonary disease, peripheral vascular and coronary artery disease, were indeed associated with stricture. A possible confounder is the correlation between smoking status, lower urinary tract symptoms and the way stricture recurrence is defined, whether by uroflowmetry or symptomatology. Stricture recurrence, as defined by uroflowmetry or recurrent LUTS, may be altered by smoking status, whereas the inability to pass a 16-Fr flexible cystoscope as employed in our study is not altered by tobacco use. ${ }^{19}$ Regardless, there is strong evidence, as hig hlighted in a recent systematic review and meta-analysis, that smoking cessation at least 1 month before all surgeries significantly decreases both wound and overall complication rates and as such should be encouraged for all preoperative patients. ${ }^{20}$

Location did not play a significant role in recurrence. Anterior urethral strictures tended to have a lesser number of recurrences; however, this was not statistically significant. This may be due to the grouping of penile and bulbar urethral strictures, as there is evidence that once separated penile strictures are more likely to recur than those in the bulbar urethra. ${ }^{11}$
There are several limitations to our study. The retrospective, single centre nature of the study limits the strength of our conclusions. Therefore, renewed effort in the form of a long-term multicentre prospective analysis is underway to further this work. We feel confident that we have done the best job possible for follow-up within the limitations of our retrospective study because we have access to an electronic medical record that captures all trips to emergency departments and all referrals to another urologist within our region; this accessed allowed us to monitor the 2 most likely methods a patient would re-present for a recurrence outside of standard postoperative care. The definition of treatment failure has been an area of debate in reconstructive literature and symposia. We feel that an objective outcome for stricture recurrence, such as the ability to pass a 16-Fr cystoscope, is a dependable primary outcome and appears to be gaining some traction in the field of reconstructive urology. ${ }^{11}$ The advantages of flexible cystoscopy include decreasing confounding variables that may alter results based on symptomatology and uroflowmetry, such as benign prostatic hyperplasia, bladder dysfunction and smoking, which may be seen concurrently in stricture patients. Furthermore, cystoscopy is a safe, widely available, office-based procedure with acceptably low rates of infection and morbidity. ${ }^{21}$

\section{Conclusion}

Urethroplasty in general is an excellent option for urethral stricture with urethral patency rates approaching 91\%. While recurrences may happen over 6 years after surgery, most $(75 \%)$ recur within the first 6 months. Preoperatively identifiable factors, such as long segment strictures $(\geq 5 \mathrm{~cm})$ as well as Lichen sclerosus, infectious and iatrogenic etiologies, are associated with an increased risk of recurrence. These preoperative factors give us more time to discuss meaningful informed consent and to provide useful information for surgical planning.

Competing interests: Dr. Kinnaird, Dr. Levine, Dr. Ambati, Dr. Zorn and Dr. Rourke all declare no competing financial or personal interests.

This paper has been peer-reviewed.

\section{References}

1. Santucci RA, Joyce GF, Wise M. Male urethral stricture disease. J Urol 2007;177:1667-74. http:// dx.doi.org/10.1016/i.juro.2007.01.041

2. Rourke K, Hickle J. The clinical spectrum of the presenting signs and symptoms of anterior urethral stricture: Detailed analysis of a single institutional cohort. Urology 2013;79:1163-7. http://dx.doi. org/10.1016/i.urology.2012.01.044

3. Stein DM, Thum DJ, Barbagli $G$, et al. A geographic analysis of male urethral stricture etiology and location. BJU Int 2013;112:830-4. 
Kinnaird et al

4. Chapple C, Barbagli G, Jordan G, et al. Consensus statement on urethral trauma. BJU Int 2004;93:1195202. http://dx.doi.org/10.1111/j.1464-410x.2004.04805.x

5. Rourke KF, Jordan GH. Primary urethral reconstruction: The cost minimized approach to the bulbous urethral stricture. J Urol 2005;173:1206-10. http://dx.doi.org/10.1097/01.ju.0000154971.05286.81

6. Burks FN, Santucci RA. Complicated urethroplasty: A guide for surgeons. Nat Rev Urol 2010;7:521-8. http://dx.doi.org/10.1038/nrurol.2010.118

7. Wood DN, Andrich DE, Greenwell TJ, et al. Standing the test of time: The long-term results of urethroplasty. World J Urol 2006;24:250-4. http://dx.doi.org/10.1007/s00345-006-0057-3

8. Eltahawy EA, Virasoro R, Schlossberg SM, et al. Long-term follow-up for excision and primary anastomosis for anterior urethral strictures. J Urol 2007;177:1803-6. http://dx.doi.org/10.1016/i. juro.2007.01.033

9. Breyer BN, McAninch JW, Whitson JM, et al. Multivariate analysis of risk factors for long-term urethroplasty outcome. J Urol 2010;183:613-7. http://dx.doi.org/10.1016/i.juro.2009.10.018

10. Charlson ME, Pompei P, Ales KL, et al. A new method of classifying prognostic comorbidity in longitudinal studies: Development and validation. J Chronic Dis 1987;40:373-83. http://dx.doi.org/10.1016/00219681(87)90171-8

11. Meeks JJ, Erickson BA, Granieri MA, et al. Stricture recurrence after urethroplasty: A systematic review. J Urol 2009;182:1266-70. http://dx.doi.org/10.1016/i.juro.2009.06.027

12. Barbagli $G$, De Angelis $M$, Romano $G$, et al. Long-term follow-up of bulbar end-to-end anastomosis: A retrospective analysis of 153 patients in a single center experience. J Urol 2007;178:2470-3. http:// dx.doi.org/10.1016/i.juro.2007.08.018

13. Morey AF, Kizer WS. Proximal bulbar urethroplasty via extended anastomotic approach-what are the limits? J Urol 2006; 175:2145-9; discussion 2149. http://dx.doi.org/10.1016/S0022-5347(06)00259-X
14. Andrich DE, Mundy AR. What is the best technique for urethroplasty? Eur Urol 2008;54:1031-41. http:// dx.doi.org/10.1016/i.eururo.2008.07.052

15. Blaschko SD, McAninch JW, Myers JB, et al. Repeat urethroplasty after failed urethral reconstruction: Outcome analysis of 130 patients. J Urol 2012;188:2260-4. http://dx.doi.org/10.1016/i. juro.2012.07.101

16. Levine MA, Kinnaird AS, Rourke K. Revision urethroplasty for recurrent urethral stricture: A comparative analysis of efficacy and outcomes. Can Urol Assoc J 2012;6:S39-40.

17. Reinke JM, Sorg H. Wound repair and regeneration. Eur Surg Res 2012;49:35-43. http://dx.doi. org/10.1159/000339613

18. Santucci RA, McAninch JW, Mario LA, et al. Urethroplasty in patients older than 65 years: Indications, results, outcomes and suggested treatment modifications. J Urol 2004;172:201-3. http://dx.doi. org $/ 10.1097 / 01 . j u .0000128810 .86535$.be

19. Koskimaki J, Hakama $M$, Huhtala $\mathrm{H}$, et al. Association of smoking with lower urinary tract symptoms. J Urol 1998;159:1580-2. http://dx.doi.org/10.1097/00005392-199805000-00046

20. Mills E, Eyawo 0, Lockhart I, et al. Smoking cessation reduces postoperative complications: A systematic review and meta-analysis. Am J Med 2011;124:144-54. e8.

21. Manson AL. Is antibiotic administration indicated after outpatient cystoscopy. J Urol 1988;140:316-7.

Correspondence: Dr. Keith Rourke, Division of Urology, Department of Surgery, University of Alberta, Edmonton, AB T6G 2B7; krourke@ualberta.ca 